\title{
ULTRASONOGRAPHIC INVESTIGATION OF OPTIC NEURITIS
}

\author{
C. DEES, R. BUIMER, A. D. DICK and H. R. ATTA \\ Aberdeen
}

\begin{abstract}
SUMMARY
A pilot echographic study was conducted to determine the incidence and severity of optic nerve swelling in acute 'idiopathic' optic neuritis and to examine cerebrospinal fluid dynamics in the subarachnoid space, employing the method of standardised echography and the ' $30^{\circ}$ test'. An attempt was made to correlate the degree of nerve swelling with the initial visual loss and with the rate and extent of recovery of vision. The visual function and echographic features of the optic nerve in 27 patients with the diagnosis of acute optic neuritis were assessed with standardised echography. A significant increase in nerve diameter was found in $\mathbf{7 4} \%$ of cases. There was a correlation between nerve swelling and the severity of initial visual loss. The authors conclude that standardised echography is a useful tool in the diagnosis of optic neuritis and may play a role in predicting the visual outcome.
\end{abstract}

Idiopathic optic neuritis is an acute demyelinating disease of the optic nerve which is essentially diagnosed clinically by a rapid onset of loss of visual acuity and colour vision, retrobulbar pain worse on ocular movement, and a relative afferent pupillary defect. ${ }^{1-3}$ This is followed by spontaneous recovery over a few weeks or months, but many patients are left with some permanent impairment of visual acuity, colour vision or contrast sensitivity. ${ }^{4,5}$ The Optic Neuritis Treatment Trial (ONTT) has shown that treatment with high-dose intravenous corticosteroids speeds the recovery of visual function in some patients but does not improve the long-term visual outcome. ${ }^{6}$ That study, however, did not employ any imaging modality to assess the degree of optic nerve swelling and was not designed to evaluate the effects of treatment in subgroups; it therefore does not identify patients with optic neuritis who may derive long-term visual benefit from steroid treatment. The ONTT has shown, however, that high-dose steroid treatment retards the development of multiple sclerosis. ${ }^{7}$

Little is known about the pathology of acute optic

Correspondence to: H. R. Atta, FRCOphth, Eye Clinic, Aberdeen Royal Infirmary, Foresterhill, Aberdeen AB9 2ZB, neuritis, ${ }^{8}$ partly because of the paucity of pathological specimens. Three pathophysiological mechanisms have been put forward as an explanation for optic nerve swelling in acute optic neuritis: (1) oedema of the nerve proper similar to swelling of white matter in acute demyelination in the central nervous system $;{ }^{9}(2)$ an increase in perineural subarachnoid fluid, ${ }^{10,11}$ (3) oedema of the nerve proper through reduction of axoplasmic flow by an acute demyelinating plaque in the optic canal. ${ }^{12}$

Standardised echography is a non-invasive, easily accessible imaging technique which aids the diagnosis of optic nerve lesions. ${ }^{13,14}$ Echography enables accurate measurements of the optic nerve because of the nerve's low reflectivity, abutting the highly reflective perineural sheath and orbital fat. If an increased optic nerve diameter is found, differentiation between fluid and solid lesions as a cause of the swelling can be achieved by repeating the measurement with the globe in $30^{\circ}$ of abduction. If increased subarachnoid fluid is present, stretching of the nerve sheath in abduction causes redistribution of fluid and net reduction of nerve diameter; this is termed a positive $30^{\circ}$ test ${ }^{15,16}$ and occurs, for example, in raised intracranial pressure. ${ }^{17}$ Absence of a reduction in width (negative $30^{\circ}$ test) indicates solid thickening of the nerve (e.g. glioma) or its sheath (e.g. meningioma) or, as in some cases of optic neuritis, either oedema of the nerve proper or a blockage of redistribution of cerebrospinal fluid (CSF), possibly by an intracanalicular lesion. ${ }^{11}$ Intracanalicular demyelinating plaques were associated with slower or poorer visual recovery in a series of patients examined with magnetic resonance imaging (MRI). ${ }^{12}$

We undertook a pilot study to image the optic nerve with standardised echography in acute idiopathic optic neuritis with the aim of determining the incidence of increased nerve diameter, assessing CSF dynamics in enlarged optic nerves by performing the $30^{\circ}$ test, and correlating these echographic findings with the severity of initial visual loss and with the rate and extent of visual recovery. 
Table I. Inclusion and exclusion criteria

\begin{tabular}{ll}
\hline Inclusion criteria & Exclusion criteria \\
\hline Typical clinical presentation of acute idiopathic optic neuritis & Age over 55 years \\
Age below 55 years & Bilateral disease \\
Presentation less than 14 days following onset of visual loss & Suspected ischaemic optic neuropathy \\
Willing to undergo echographic examination & Recurrent optic neuritis \\
\hline
\end{tabular}

\section{PATIENTS AND METHODS}

All patients who presented to the eye department of Aberdeen Royal Infirmary between May 1991 and August 1993 with the clinical diagnosis of optic neuritis as described in the Introduction ${ }^{1,2}$ were invited to enter the study. Inclusion and exclusion criteria are listed in Table I. The history and clinical examination included Snellen visual acuity, colour vision score with Ishihara pseudo-isochromatic plates, pupillary reaction and funduscopy. Subsequent echography of the optic nerve and Dicon suprathreshold visual fields were performed.

B-scan and standardised A-scan ultrasound assessment of the optic nerve were performed by a single
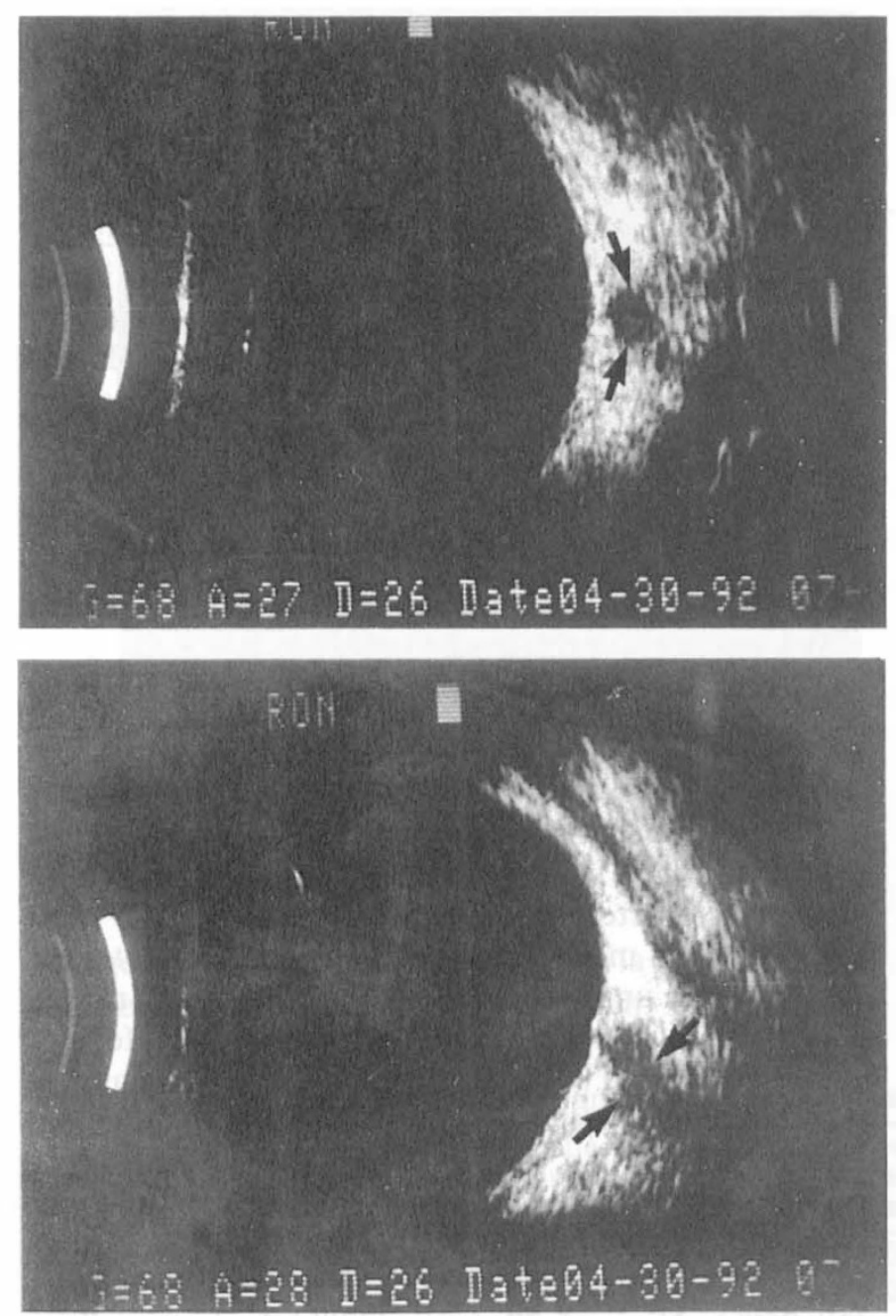

observer (H.R.A.) as described previously. ${ }^{14}$ The instruments used were the Ophthascan-S B \& A scan and the Ophthascan-Mini A (Alcon Laboratories). B-scan was utilised first to screen the orbit and rule out orbital mass. Transverse (cross-section) and longitudinal scans of both optic nerves were obtained for qualitative assessment of nerve diameter (Fig. 1). Standardised A-scan at 'tissue (T) sensitivity' was then employed to trace the nerve antero-posteriorly in order to measure its width and assess its reflectivity. Three traces deemed to be of 'high quality' (i.e. showing tall and smooth sheath spikes) were selected for measurement (Fig. 2). This was performed using the freeze-frame facility and
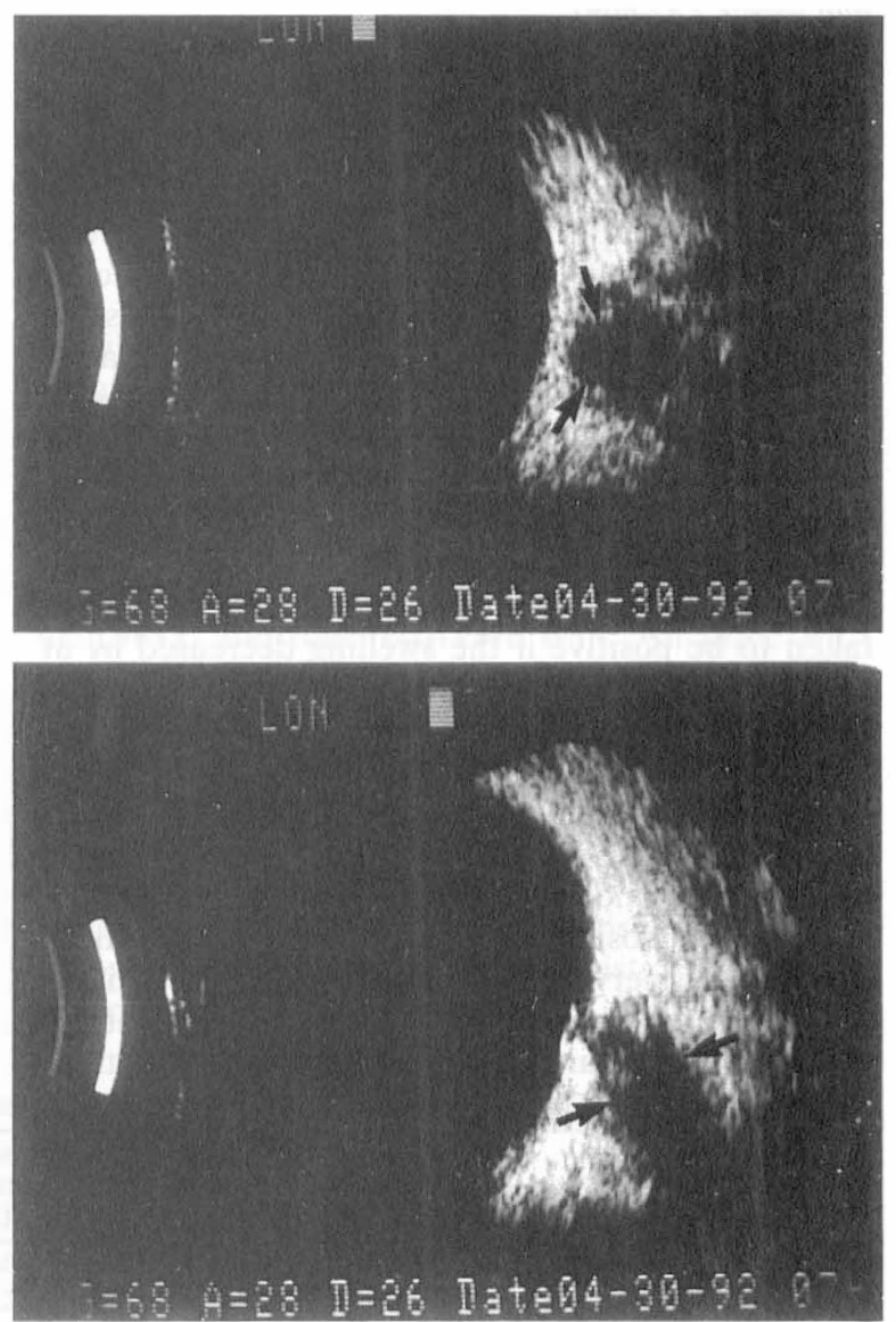

Fig. 1. B-scan display of normal optic nerve versus optic neuritis. Top left: Transverse B-scan of normal optic nerve (black arrows). Top right: transverse B-scan in optic neuritis. Note the widening of the nerve void (black arrows). Bottom left: Longitudinal B-scan of normal optic nerve (black arrows). Bottom right: Longitudinal B-scan in optic neuritis. Note the widening of the nerve void (black arrows). 

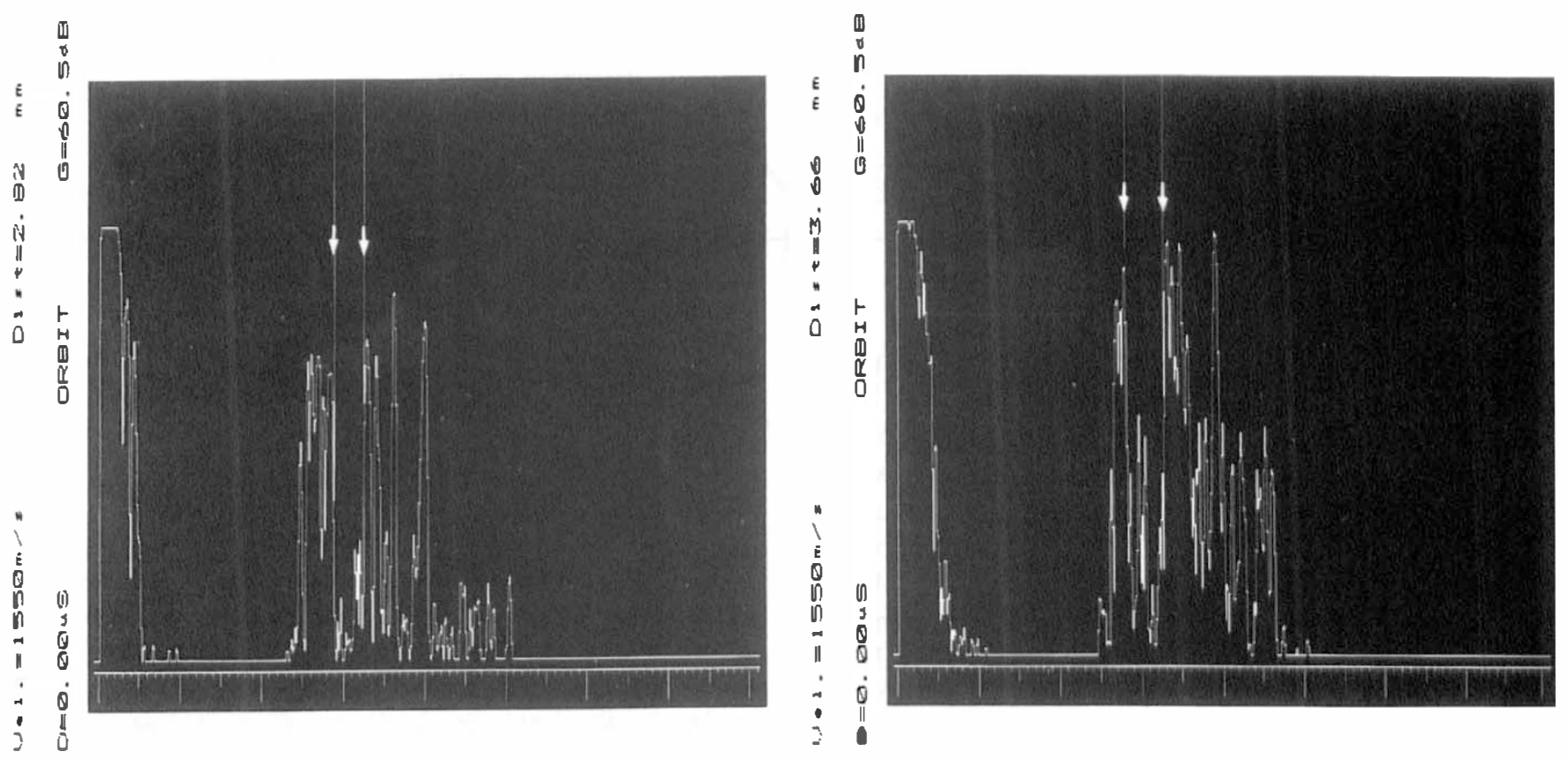

Fig. 2. Standardised A-scan display of normal optic nerve versus optic neuritis. Left: A-scan of normal optic nerve. Right: Ascan in optic neuritis. White arrows indicate optic nerve (sheath) diameter. Note the increased diameter in optic neuritis (3.66 mm versus $2.82 \mathrm{~mm}$ ).

electronic gates, and employing a sound velocity of $1550 \mathrm{~m} / \mathrm{s}$. It is important to emphasise that nerve diameters obtained by this method may not be a true anatomical 'perpendicular' cross-section. ${ }^{18}$ Nevertheless, the results are consistent and reproducible as the test was uniformly performed using the same instruments, decibel gain, examiner and examination technique. Both optic nerve diameters were assessed without knowledge of which eye was affected, followed by a $30^{\circ}$ test. The unaffected optic nerves were thus used as controls. Nerve swelling was present if the diameter measured at least $0.3 \mathrm{~mm}$ larger than the contralateral nerve. ${ }^{16}$ The $30^{\circ}$ test was taken to be positive if the swelling decreased by at least $10 \%$ on abduction. ${ }^{15,16}$ Fig. 3 shows an example of reduction in echographic nerve diameter on $30^{\circ}$ testing.

Patients were divided, according to the echographic findings, into three groups: group I, those with normal optic nerve; group II, those with swollen nerve and a positive $30^{\circ}$ test; and group III, those with swollen nerve and a negative $30^{\circ}$ test. Patients were then followed up with repeat assessments of visual acuity, colour vision and funduscopy until their condition resolved or stabilised.

\section{RESULTS}

\section{Clinical Details}

Thirty-one patients were initially referred for the study. Three did not fulfil the diagnostic criteria of optic neuritis and one was excluded from analysis because of bilateral involvement. Twenty-seven patients were thus included in the initial clinical and echographic analysis, and 25 completed the study. Clinical features are summarised in Table II. The female to male ratio was $2: 1$ (18 females, 9 males). Mean age was 35 years (range 13-50 years). A relative afferent pupillary defect was present in all cases $(100 \%)$, and reduced colour vision, defined as missing 2 or more of 17 pseudo-isochromatic plates, was present in 22 of 27 cases (81\%). Pain on ocular movements was present in 23 of 27 patients $(85 \%)$.

Mean delay from onset of symptoms to performing ultrasound was 12 days. Funduscopy revealed swelling of the optic disc in 10 of 27 cases $(37 \%)$, normal disc in $15(56 \%)$, and was equivocal in 2 cases $(7 \%)$.

\section{Echography (see Table III)}

Twenty of 27 cases (74\%) had swelling of the affected optic nerve on standardised A-scan ultrasound (groups II and III). In these patients the average diameter of affected nerves was $3.60 \mathrm{~mm}$ (range 3.0-4.4 mm), whereas the average diameter of contralateral unaffected nerves was $2.82 \mathrm{~mm}$ (range 2.3-3.1 mm). The increase in diameter of the affected nerve compared with the unaffected contralateral nerve averaged $0.8 \mathrm{~mm}$ (range $0.4-1.3 \mathrm{~mm}$ ). Of those cases with swollen nerves, 11 of $27(41 \%)$ had a positive $30^{\circ}$ test, where the average decrease in nerve diameter on abduction was $0.61 \mathrm{~mm}$ (i.e. $17 \%$ of the diameter in primary gaze), range $0.3-0.9 \mathrm{~mm}$ $(10-25 \%)$. Nine of 27 cases $(33 \%)$ had a swollen nerve with negative $30^{\circ}$ test. Seven of 27 cases $(26 \%)$ had no discernible swelling on echography, where the average affected nerve diameter was $2.93 \mathrm{~mm}$ 


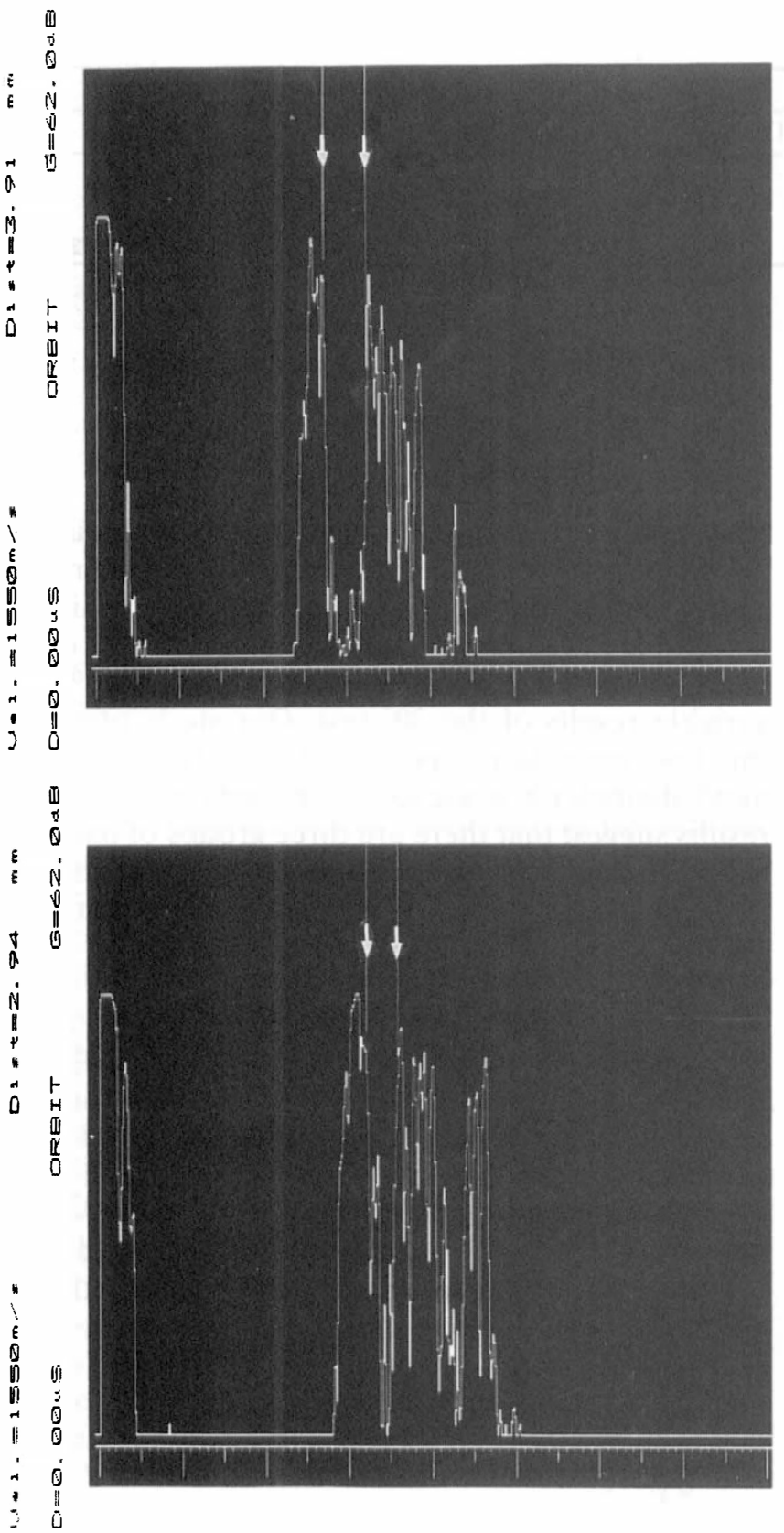

Fig. 3. Example of swollen nerve and positive $30^{\circ}$ test. White arrows indicate optic nerve sheaths. Top: Measurement in primary position of gaze $=3.91 \mathrm{~mm}$. Bottom: Measurement with globe in $30^{\circ}$ of abduction; note the reduced optic nerve (sheath) diameter $=2.94 \mathrm{~mm}(25 \%$ reduction $)$.

(range 2.7-3.1 mm), compared with a contralateral unaffected nerve diameter of $2.89 \mathrm{~mm}$. The average
Table II. Optic neuritis: clinical features in 27 cases

\begin{tabular}{lrl}
\hline Female : male ratio & $2: 1$ & \\
Mean age & 35 years (range 13-50) \\
Relative afferent pupillary defect & $27 / 27$ & $(100 \%)$ \\
Orbital pain & $23 / 27$ & $(85 \%)$ \\
Initial visual acuity & & \\
$\quad$ Hand movements (HM) & $5 / 27$ & $(19 \%)$ \\
Counting fingers (CF) & $6 / 27$ & $(22 \%)$ \\
6/60 & $0 / 27$ & \\
$6 / 18-6 / 36$ & $9 / 27$ & $(33 \%)$ \\
6/6-6/12 & $7 / 27$ & $(26 \%)$ \\
Impaired colour vision (Ishihara) & $22 / 27$ & $(81 \%)$ \\
Visual field (Dicon) & & \\
Central scotoma & $10 / 27$ & $(37 \%)$ \\
Paracentral scotoma & $7 / 27$ & $(26 \%)$ \\
Other & $3 / 27$ & $(11 \%)$ \\
Normal field & $3 / 27$ & $(11 \%)$ \\
$\quad$ No test performed & $4 / 27$ & $(15 \%)$ \\
Disc swelling & $10 / 27$ & $(37 \%)$ \\
Good recovery (VA & $24 / 27$ & $(89 \%)$ \\
\hline
\end{tabular}

time interval between onset of symptoms of optic neuritis and performing echography in this group was similar (11 days) to the overall average (12 days).

\section{Visual Acuities Versus Echography (see Table IV)}

In the group of patients with echographically normal nerves $(n=7), 3$ had a visual acuity (VA) of $6 / 6$ to $6 / 12$ and 4 had VA $6 / 18$ to $6 / 36$ on presentation. In cases with echographically swollen nerve $(n=20), 4$ had VA $6 / 6$ to $6 / 12$, 5 had VA 6/18 to $6 / 36$, and 11 had VA $6 / 60$ or worse on presentation. This distribution was similar for the group with a negative $30^{\circ}$ test compared with the group with a positive $30^{\circ}$ test. Of patients who completed the study $(n=25), 22$ recovered 6/9 or better vision. The period of follow-up varied from 6 weeks in patients who recovered quickly to 6 months in patients who recovered more slowly. Two recovered to no better than $6 / 12$, and one recovered 6/18. All three with poorer visual outcome had had an echographically swollen optic nerve on presentation. No patient with an echographically normal nerve had an initial VA of worse than $6 / 36$ or a final VA of less than $6 / 9$ (Figs. 4, 5).

Fig. 6 correlates initial VA with the diameter of the affected optic nerve, without subdivision into groups according to echographic characteristics. The correlation coefficient $(r)$ was $0.72\left(r^{2}=0.52\right)$, and the

Table III. Average optic nerve diameter in acute optic neuritis (mm)

\begin{tabular}{|c|c|c|c|c|}
\hline & $\begin{array}{c}\text { Diameter of affected } \\
\text { optic nerve } \\
(\mathrm{mm})\end{array}$ & $\begin{array}{c}\text { Diameter of contralateral } \\
\text { optic nerve } \\
(\mathrm{mm})\end{array}$ & $\begin{array}{c}\text { Difference between the } \\
\text { two nerves } \\
(\mathrm{mm})\end{array}$ & $\begin{array}{c}\text { Percentage decrease } \\
\text { on } 30^{\circ} \text { test } \\
(\mathrm{mm})\end{array}$ \\
\hline Group I $(n=7)$ & $2.93(0.13)$ & $2.89(0.06)$ & $0.04(0.12)$ & $0.3 \%$ \\
\hline Group II $(n=11)$ & $3.58(0.20)$ & $2.86(0.21)$ & $0.72(0.16)$ & $17 \%$ \\
\hline Group III $(n=9)$ & $3.63(0.42)$ & $2.77(0.21)$ & $0.86(0.34)$ & $-4 \%^{a}$ \\
\hline
\end{tabular}

Values in parentheses are standard deviations.

Group I, nerve not swollen; group II, nerve swollen, positive $30^{\circ}$ test; group III, nerve swollen, negative $30^{\circ}$ test.

${ }^{a}$ Denotes that the nerve diameter increases on $30^{\circ}$ testing, an observation similarly noted previously. 
Table IV. Initial visual acuity in optic neuritis and echographic features of the optic nerve

\begin{tabular}{lccc}
\hline & \multicolumn{3}{c}{ Initial visual acuity } \\
\cline { 2 - 4 } & $6 / 6-6 / 12$ & $6 / 18-6 / 36$ & $6 / 60$ or worse \\
\hline Normal nerve $(n=7)$ & 3 & 4 & 0 \\
Enlarged nerve, positive $30^{\circ}$ test $(n=11)$ & 2 & 3 & 6 \\
Enlarged nerve, negative $30^{\circ}$ test $(n=9)$ & 2 & 2 & 5 \\
\hline
\end{tabular}

graph illustrates the tendency for more severely swollen nerves to be associated with more profound initial loss of vision. The correlation between initial nerve diameter and visual outcome is less striking (Fig. 7), but the graph does illustrate that a final VA of less than $6 / 9$ occurred only with an initial nerve diameter of more than $3.2 \mathrm{~mm}$.

The rate of visual recovery, expressed as the average length of time required to recover VA to 6/9 or better was 4 weeks in cases with echographically normal nerves (range 2-6 weeks); 4.7 weeks in cases with swollen nerves and positive $30^{\circ}$ test (range 3-6 weeks) and 5 weeks in cases with swollen nerve and negative $30^{\circ}$ test (range 1-13 weeks) (differences not statistically significant).

\section{Disc Oedema}

Of cases with an echographically normal optic nerve $(n=7), 2$ had clinical disc oedema. Moreover, of cases with an echographically swollen optic nerve $(n=20)$, only 8 had disc oedema. Although the range of initial VA was similar in patients with and without disc oedema (6/18-HM and 6/9-HM, respectively), the

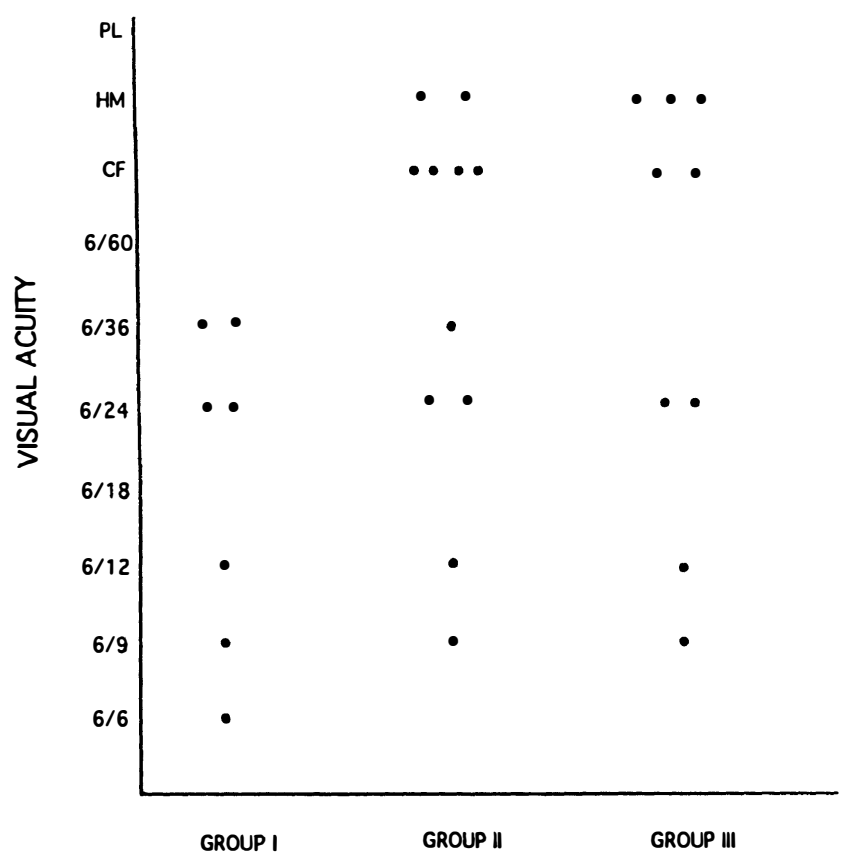

Fig. 4. Initial visual acuity and echographic features of optic nerve. Group I, normal nerve; group II, enlarged nerve, positive $30^{\circ}$ test; group III, enlarged nerve, negative $30^{\circ}$ test. average initial VA did differ, being 6/48 and 6/24, respectively.

\section{DISCUSSION}

Standardised echography can provide valuable information in the diagnosis and management of acute idiopathic optic neuritis. Echographically detectable swelling of the optic nerve in optic neuritis has been described before ${ }^{10,11,19,20}$ with variable results of the $30^{\circ}$ test. Our study provides the first quantitative prospective analysis of optic nerve diameter in acute idiopathic optic neuritis. The results suggest that there are three groups of patients with different echographic characteristics: normal nerves, swollen nerves with a positive $30^{\circ}$ test and swollen nerves with a negative $30^{\circ}$ test $(26 \%, 41 \%$ and $33 \%$, respectively).

Echographically normal optic nerves were associated with limited visual loss (better than 6/60) and recovery to $6 / 9$ or better in all cases, whereas echographically swollen nerves were associated with visual loss to less than $6 / 60$ in $55 \%$ of cases. It is of interest that all eyes presenting with an initial visual loss of $6 / 60$ or worse had echographically detectable swelling of the optic nerve when compared with the

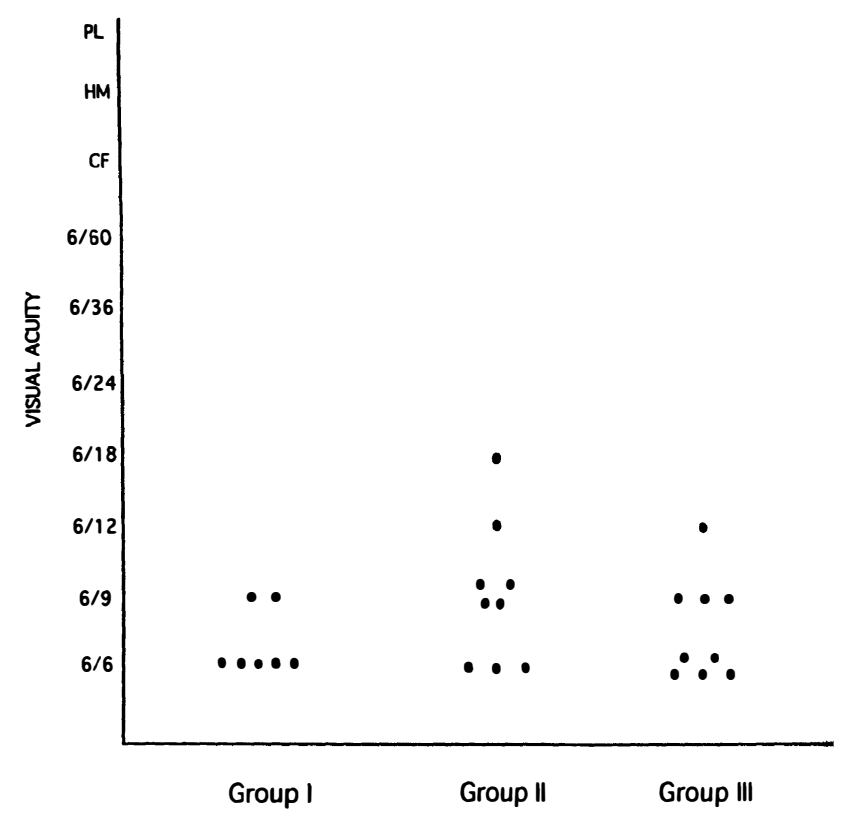

Fig. 5. Final visual acuity and initial echograhic features of optic nerve. group I, normal nerve; group II, enlarged nerve, positive $30^{\circ}$ test; group III, enlarged nerve, negative $30^{\circ}$ test. 


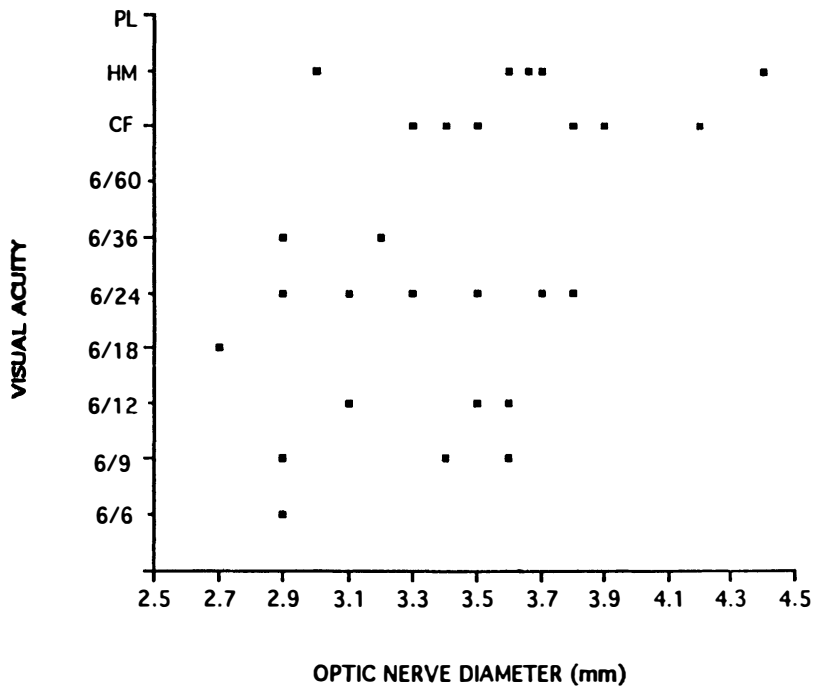

Fig. 6. Visual acuity and optic nerve diameter on initial presentation.

contralateral unaffected nerve. This association was a significant finding. In this study we did not demonstrate, as one may postulate because of intracanalicular blockage of axoplasmic flow, a poorer visual outcome in cases with a negative $30^{\circ}$ test. Clinical swelling of the optic disc head occurred in echographically swollen as well as in echographically normal nerves. This is consistent with the suggestion ${ }^{12}$ that disc oedema is more likely to indicate anterior location of the inflammation than is a generalised swelling of the optic nerve.

Although numbers in this study are relatively small, the results do show a correlation between the clinical course and the echographic appearance of the optic nerve. Therefore, of the aims set out in this study, we were able to determine the incidence of nerve swelling in 'idiopathic optic neuritis' and the correlation between nerve swelling and initial visual loss. We were unable to find a statistically significant difference in the degree of visual loss or outcome between patients with swollen nerve and a negative $30^{\circ}$ test and those with swollen nerve and a positive $30^{\circ}$ test. Subtle changes in colour vision and contrast sensitivity may have been missed, however, since we did not perform sophisticated tests for such visual functions. ${ }^{4,5}$

Further investigations are required, both to confirm our findings and to determine whether there is any prognostic indication from the echographic appearance of the optic nerve. If it proves possible to identify, on echographic characteristics, a subgroup of cases of optic neuritis with a poorer visual outcome, then such a subgroup may benefit from steroid treatment or other means of reducing inflammatory nerve swelling. Future echographic investigations in acute optic neuritis will also need to take into account any temporal changes in echographic appearance of the optic nerve that

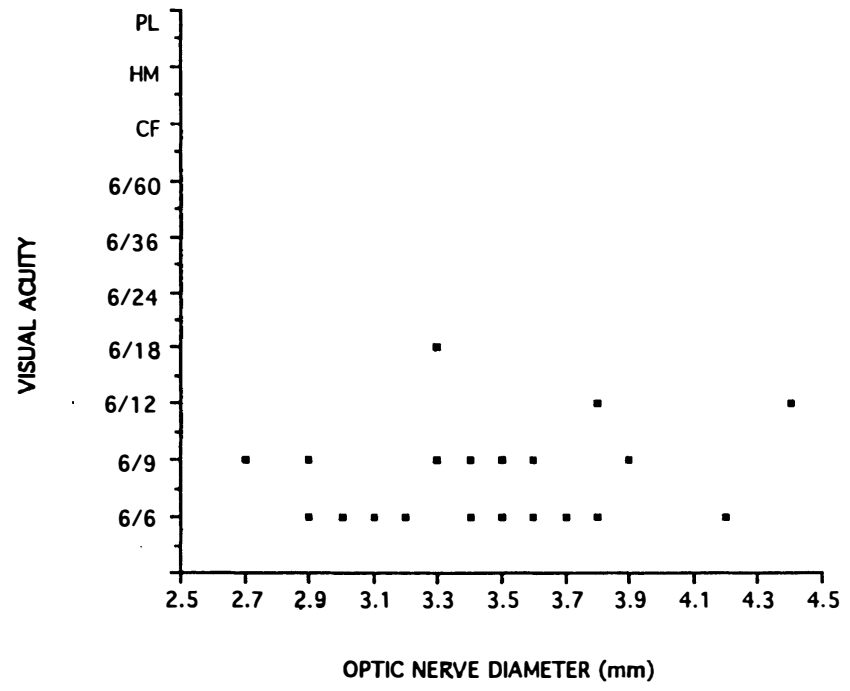

Fig. 7. Visual acuity after recovery and initial optic nerve diameter.

may occur during the course of the disease, and the effect which the location of the acute demyelinating plaque within the optic nerve has on the echographic appearance. Our study demonstrated a role for echography in the diagnosis and management of optic neuritis. Echography will help confirm the diagnosis, exclude other (compressive) lesions as a cause of optic nerve dysfunction, and may provide a prognostic indication of visual recovery.

Key words: Echography, Optic nerve, Optic neuritis, Ultrasound.

\section{REFERENCES}

1. Miller NR, editor. Walsh \& Hoyt's clinical neurophthalmology. 4th ed. Baltimore: Williams and Wilkins, 1982:227.

2. Optic Neuritis Study Group. The clinical profile of optic neuritis. Arch Ophthalmol 1991;109:1673-8.

3. Perkin GD, Rose FC. Optic neuritis and its differential diagnosis. Oxford: Oxford Medical Publications, 1979:91-101.

4. Bradley WG, Whitty CWM. Acute optic neuritis: its clinical features and their relation to prognosis for recovery of vision. J Neurol Neurosurg Psychiatry 1967;30:531-8.

5. Slamovits TL, et al. Visual recovery in patients with optic neuritis and visual loss to no light perception. Am J Ophthalmol 1991;11:209-14.

6. Beck RW, et al. A randomised, controlled trial of corticosteroids in the treatment of acute optic neuritis. N Engl J Med 1992;326:581-8.

7. Beck RW, Cleary PA, Trobe JD, et al. The effect of corticosteroids for acute optic neuritis on the subsequent development of multiple sclerosis. N Engl J Med 1993;329:1764-9.

8. Toussaint $\mathrm{D}$, et al. Clinicopathological study of the visual pathways, eyes and cerebral hemispheres in 32 cases of disseminated sclerosis. J Clin Neuro-Ophthalmol 1983;3:211-20.

9. Adams CWM, et al. Inflammatory vasculitis in multiple sclerosis. J Neurol Sci 1985;69:269-83.

10. Byrne SF, Green RL. Ultrasound of the eye and orbit. Mosby-Year Book, 1992:405-9. 
11. Ossoinig KC. Standardised echography of the optic nerve. Doc Ophthalmol Proc Ser 1990;55:75-7.

12. Miller DH, et al. Magnetic resonance imaging of the optic nerve in optic neuritis. Neurology 1988;38:175-9.

13. Ossoinig KC. Standardised echography: basic principles, clinical applications and results. Int Ophthalmol Clin 1979;19:127-210.

14. Atta HR. Imaging of the optic nerve with standardised echography. Eye 1988;2:358-66.

15. Byrne SF. Evaluation of the optic nerve with standardised echography. In: Smith JL, editor. Neuroophthalmology now. New York: Field, Raicha and Associates, 1986:45-66.

16. Ossoinig KC, Cennamo G, Byrne SF. Echographic differential diagnosis of optic nerve lesions. Doc Ophthalmol Proc Ser 1981;29:327-31.

17. Hupp SL, Glaser JS, Byrne SF. Optic nerve sheath decompression. Arch Ophthalmol 1987;105:386-9.

18. Hasenfratz G. Experimental studies on the display of the optic nerve. In: Ossoinig KC, editor. Ophthalmic echography. The Hague: Martinus Nijhoff/W Junk, 1987:587-602.

19. Byrne SF, Green RL. Orbital echography. In: Tasman W, Jaeger EA, editors. Duane's clinical ophthalmology, vol. 1, revised ed. Philadelphia: JB Lippincott, 199:Chap. 26.

20. Gans MS, Byrne SF, Glaser JS. Standardised A-scan echography in optic nerve disease. Arch Ophthalmol 1987;105:1232-6. 